Peter REICHETSEDER ${ }^{1}$

\title{
THE CONCEPT OF WELL INTEGRITY IN GAS PRODUCTION ACTIVITIES
}

\author{
KONCEPCJA INTEGRALNOŚCI ODWIERTÓW PRZY PRODUKCJI GAZU
}

\begin{abstract}
Shale gas production in the US, predominantly from the Marcellus shale, has been accused of methane emissions and contaminating drinking water under the suspicion that this is caused by hydraulic fracturing in combination with leaking wells. Misunderstandings of the risks of shale gas production are widespread and are causing communication problems. This paper discusses recent preliminary results from the US Environmental Protection Agency (EPA) draft study, which is revealing fact-based issues: EPA did not find evidence that these mechanisms have led to widespread, systemic impacts on drinking water resources in the United States, which contrasts many broad-brushed statements in media and public. The complex geological situation and extraction history of oil, gas and water in the Marcellus area in Pennsylvania is a good case for learnings and demonstrating the need for proper analysis and taking the right actions to avoid problems. State-of-the-art technology and regulations of proper well integrity are available, and their application will provide a sound basis for shale gas extraction.
\end{abstract}

Keywords: shale gas, environmental impact, produced water, flowback water

\section{Perceived risks of hydraulic fracturing and other challenges}

Shale gas has become a projection surface for vague concerns in the public, especially the word "fracking" is characterized with "controversial" being the most benign label. "Gasland" has introduced general skepticism in the minds of many people, and the well-known "Truth Effect" [1], often repeated statements are creating firm believes, seems to have established a negative "perceived reality" of shale gas. Consequently, academia and industry on one side and public opinion on the other are often divided in their opinions on the benefits of shale gas.

At the same time the impact of shale gas on domestic production in the U.S. and energy situation is demonstrating the immense potential of this resource. Shale gas production in US has grown enormously and the Marcellus Shale in Pennsylvania (Fig. 1) presently contributes $40 \%$ of US shale gas production [2].

\footnotetext{
${ }^{1}$ Upstream - Energy - Consulting, Germany, email: reichetseder@t-online.de Institute of Petroleum Engineering, Technische Universität Clausthal, Adolph-Roemer-Strasse 2A, D-38678 Clausthal-Zellerfeld, Germany
} 

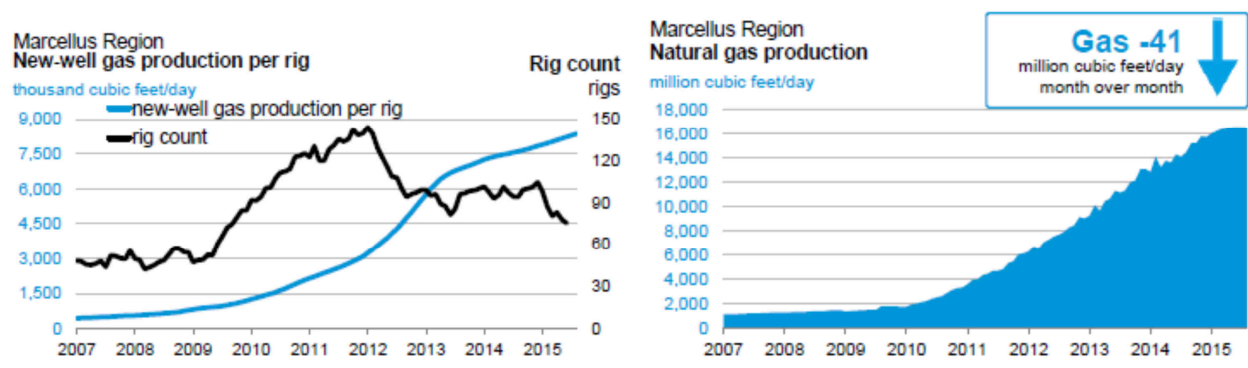

Fig. 1. Marcellus Gas Production [2]

\section{Results of the recent EPA draft study}

In 2010 the Congress urged the U.S. Environmental Protection Agency [3] to conduct a study of the potential impacts of hydraulic fracturing for oil and gas on drinking water resources. In response, EPA developed a research plan (Plan to Study the Potential Impacts of Hydraulic Fracturing on Drinking Water Resources) that was reviewed by it is Science Advisory Board (SAB) and issued in 2011. A progress report on the study (Study of the Potential Impacts of Hydraulic Fracturing on Drinking Water Resources: Progress Report), detailing the EPA's research approaches and next steps, was released in late 2012 and was followed by a consultation with individual experts convened under the auspices of the SAB.

The recent EPA study (Draft!) [3] includes the development of several research projects, extensive review of the literature and technical input from state, industry, and non-governmental organizations as well as the public and other stakeholders and followed by a series of technical roundtables and in-depth technical workshops. The study is designed to address research questions posed for each stage of the hydraulic fracturing water cycle being: Water Acquisition, Chemical Mixing, Flowback and Produced Water, Wastewater Treatment and Waste Disposal, and Well Injection. This chapter investigates the possible impacts of the injection and fracturing process on drinking water resources.

The report includes both the literature review and results from the research projects conducted as part of the EPA's study. It will undergo independent, external peer review in accordance with Agency policy and all of the peer review comments received will be considered in the development of the final report.

\section{Major Findings - still preliminary - present strong indications!}

EPA's assessment concludes there are above and below ground mechanisms by which hydraulic fracturing activities have the potential to impact drinking water resources. These mechanisms include water withdrawals in times of, or in areas with, low water availability; spills of hydraulic fracturing fluids and produced water; fracturing directly into underground drinking water resources; below ground migration of liquids and gases; and inadequate treatment and discharge of wastewater.

EPA says, that it "did not find evidence that these mechanisms have led to widespread, systemic impacts on drinking water resources in the United States. Of the potential mechanisms identified in its report, EPA found specific instances where one or more mechanisms led to impacts on drinking water resources, including contamination of 
drinking water wells. The number of identified cases, however, was small compared to the number of hydraulically fractured wells."

EPA still cautions, that the "finding could reflect a rarity of effects on drinking water resources, but may also be due to other limiting factors. These factors include: insufficient pre- and post-fracturing data on the quality of drinking water resources; the paucity of long-term systematic studies; the presence of other sources of contamination precluding a definitive link between hydraulic fracturing activities and an impact; and the inaccessibility of some information on hydraulic fracturing activities and potential impacts."

However, it would be very surprising, if the findings of the study would be turned upside down during the Peer Review process. The author therefore takes the results as a good and relevant indication of the quality of the shale gas production process in the US.

EPA gives specific comments with relevance to well integrity topics as follows (see also Fig. 2):

- $\quad>3 \%$ of 23,000 wells do not have cement across a portion of the casing installed through the protected ground water resource.

- Burst of casing led to a "blowout" during fracturing (Killdeer, North Dakota).

- Inadequately cemented casing in a HF' $\mathrm{d}^{2}$ well contributed to the buildup of natural gas and high pressures alongside the outside of a production well (Bainbridge, Ohio).

- Inadequate cement placement in a production well allowed methane and benzene to migrate along the production well and through natural faults and fractures to drinking water resources (Mamm Creek gas field, Colorado).

- Fracturing older wells may also increase the potential for impacts; EPA estimates that $6 \%$ of 23,000 oil and gas production wells were drilled more than 10 years before being HF'd in 2009 or 2010 . Aging of wells can also contribute to casing degradation (eg corrosion through $\mathrm{H}_{2} \mathrm{~S}, \mathrm{CO}_{2}$, brines).

- Antrim Shale (Michigan) and New Albany Shale (Illinois/Indiana/Kentucky) are at shallow depths $(30-580 \mathrm{~m})$ with little vertical separation. $20 \%$ of 23,000 wells being HF' $d$ had less than $610 \mathrm{~m}$ distance between the shallowest HF'd zone and the protected groundwater table.

- Places with oil and gas and drinking water resources co-exist in the same formation, where $\mathrm{HF}$ was conducted in the formation containing drinking water. Occurrence appears to be low, concentrated in the western U.S.

- Migration of formation fluids into underground drinking water resources may also occur via production or injection wells near HF operations. Well spacing is important: in the Woodford Shale (Oklahoma) the likelihood of well communication was $<10 \%$ between wells $1220 \mathrm{~m}$ apart, but has increased to $50 \%$ between wells less than $300 \mathrm{~m}$ apart.

- Older or inactive wells near a HF operation may pose even greater potential for impacts. Old wells may not have been plugged properly (before 1950 with little or no cement). The Interstate Oil and Gas Compact Commission estimates that > 1 Million wells have been drilled in the US prior to a formal regulatory system being in place, the status of many is unknown ("Orphan Wells").

\footnotetext{
${ }^{2}$ HF: Hydraulic Fracturing
} 


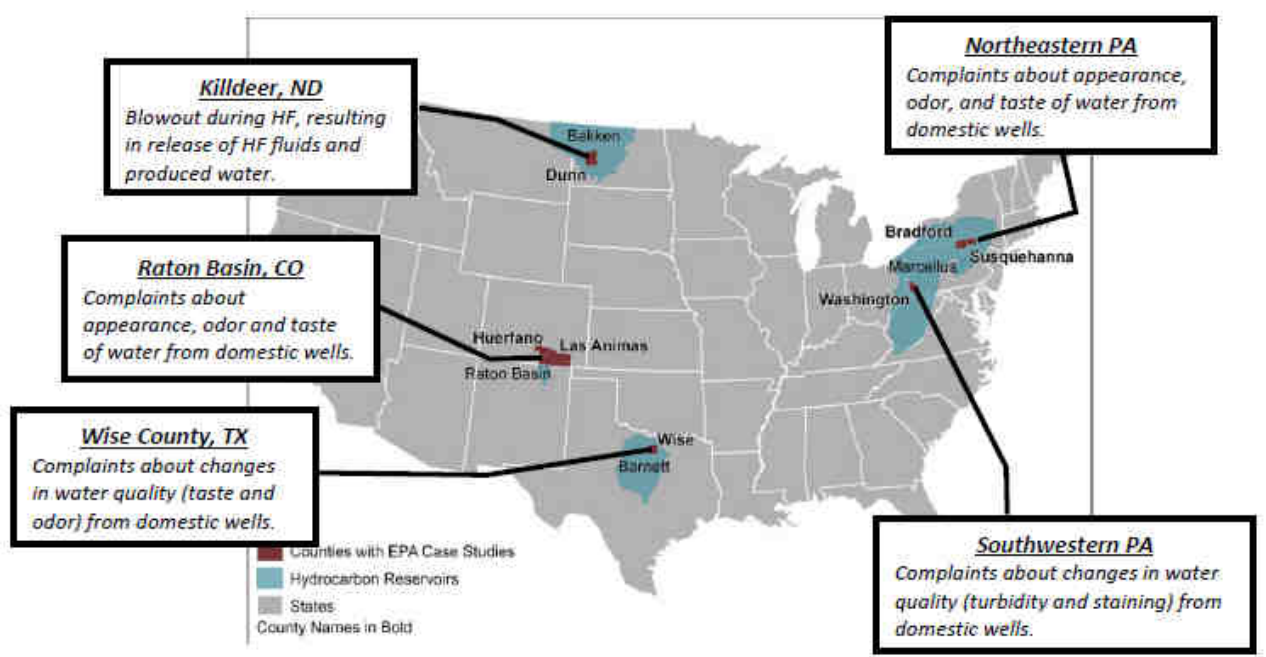

Fig. 2. Example cases discussed in the EPA draft study [3]

These findings are pointing towards few, but essential issues relating to well integrity:

$>$ Proper well design and construction (casing and cement design and cement placement) can be considered a state-of-the-art technology, which in US several cases has not been followed during the hype of shale gas development and trying to achieve low-cost results; the development of shale gas has been driven mainly by small/medium independents.

$>$ Old wells need to be evaluated before being used for HF; non-active old wells can present a leakage risk, which $e g$ is well known from conversions of gas fields into gas storage.

$>$ The vertical and horizontal separation between the location of HF and drinking water formations needs to be respected; measurements of thousands of fracturing operations have produced reliable data for appropriate separation.

From a professional view point these problems highlighted in the EPA study are neither new nor unexpected. If well design and construction procedures include evaluation of old wells and rules for keeping a safe distance between HF'd formation and protected groundwater layers are followed properly, such problems can be avoided.

\section{Learning from Pennsylvania}

The Marcellus region, because of special geological and historic reasons, has become a hotspot for problems with contaminated drinking water. In a study from Duke University, Osborn et al [4] argue quite firmly "In aquifers overlying the Marcellus and Utica shale formations of northeastern Pennsylvania and upstate New York, we document systematic evidence for methane contamination of drinking water associated with shale gas extraction."

Molofsky et al [5] published a comprehensive investigation of more than 1700 water wells sampled and tested prior to proposed gas drilling in the Susquehanna County, PA; 
this study concludes methane to be ubiquitous ${ }^{3}$ in shallow groundwater with a clear correlation of methane concentrations with surface topography. Specifically, water wells located in lowland valley areas seem to exhibit significantly higher dissolved methane levels than water wells in upland areas, with no relation to proximity of existing gas wells. The correlation of methane concentrations with elevation would indicate that, on a regional level, elevated methane concentrations in groundwater are a function of geologic features, rather than shale gas development.

The source of this dissolved methane is important with regard to understanding the potential effects of ongoing shale gas development and appropriate measures for protection of water resources. Figure 3 depicts typical situations where methane from different sources may be found in contaminated water wells. Forensics using isotopes and noble gases allow to distinguish between biogenic and also different thermogenic gases [6].

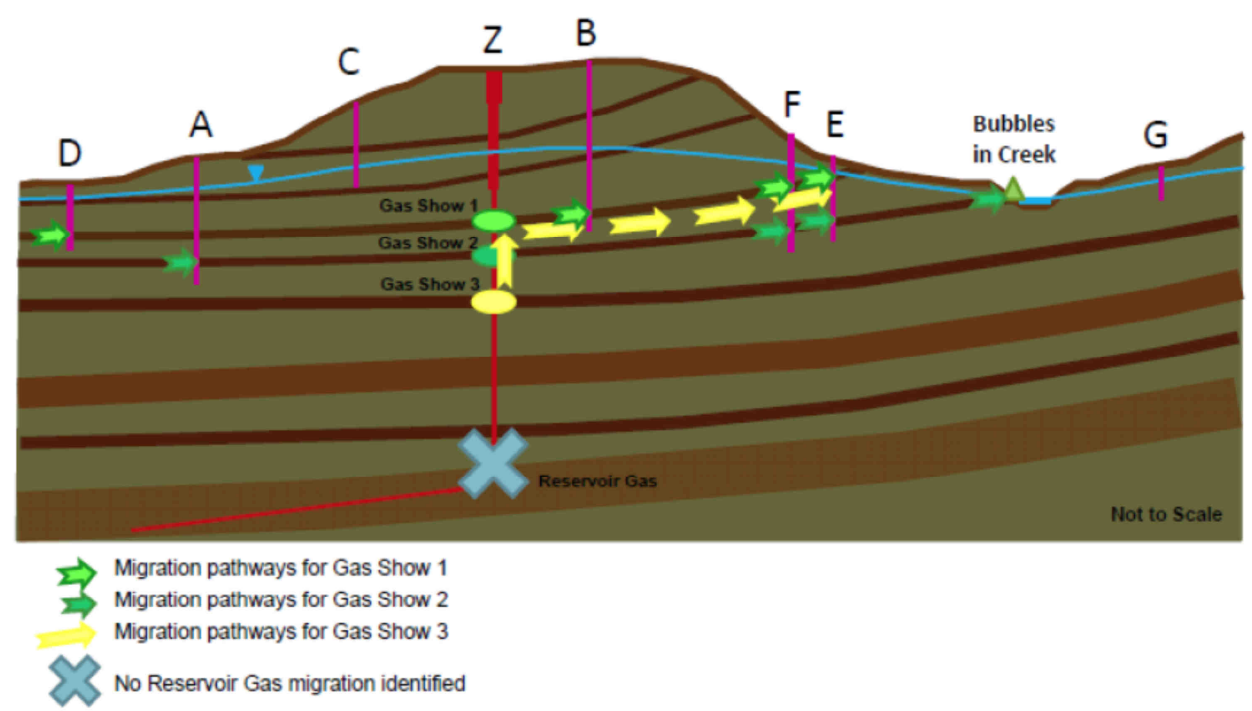

Fig. 3. Gas migration pathways [6]

Molofsky et al [5] show that the isotope signatures of the Duke study's thermogenic methane samples were more consistent with those of shallower Upper and Middle Devonian deposits overlying the Marcellus shale. These findings indicate that the methane could have originated entirely from sources above the Marcellus, not related to HF activities! This conclusion has also been shared meanwhile by Darrah et al [7] from Duke University based on investigation on 113 drinking-water wells in Pennsylvania and 20 samples from the Barnett area in Texas, found methane contamination in ground water table caused by impaired well construction, but "not fracing".

Investigations in PA demonstrate that HF did not cause methane contamination in the groundwater, but rather flawed well design by leaving a section of geology containing "stray gas" without intermediate casing and without cement. In these cases stray gas could

\footnotetext{
${ }^{3}$ Pennsylvania is known as the richest coal province in the US. Coal has undoubtedly led to gas migrating into groundwater formations and therefore is not uncommon in water wells.
} 
migrate upwards into the groundwater table. Reichetseder [8] elaborates in more detail on the stepwise investigative process to identify the core of the issues.

Before embarking in shale drilling campaigns it is crucially important to understand the local/regional geology also above the targeted shale formations. If shallow gas (or "stray gas") is present, extensive work has to go into baseline studies and planning for the design and construction of wells. Well design, construction and monitoring have to be performed with appropriate professionalism. This is the purpose of "Well Integrity Management". We can take following lessons:

- Pennsylvania has a complex geology with oil and gas production and water production over many decades.

- Water wells are producing from/connected to active methane bearing formations.

- Investigations from Ingraffea et al [9] are mainly of statistical nature; the numbers about "well failures" are not plausible: as long as there are no broken barriers, there is no well failure [10].

- Latest studies from Darrah et al [7] conclude that there is no evidence of a connection between HF of the shale and groundwater formation, neither in Marcellus nor Barnett, but they identified several groups of wells where stray gas (from formations above the Marcellus shale) escaped through leaking annuli or defective casings.

- Shale gas operators until 2010 often applied a "cheap" casing string design with surface casing and production casing only, but without intermediate casing. This problem has since been eliminated by stricter US directives for well design and cementing (PA 2012, Ohio 2014).

- European guidelines (UK, NORSOK) and API (since 2010) would not tolerate such design.

- Results of the EPA draft study 2015 can be considered in line with above statements.

\section{Well Integrity}

Countries historically have developed different regulations depending on geological situation in the hydrocarbon basin, evolution of experience over decades, technology development and environmental stringency.

US: The most comprehensive and also in the oil and gas industry widely used system of standards stems from the American Petroleum Institute (API), which has developed standards for oil and naturals gas operations since 1924. API's formal consensus process is accredited by the American National Standards Institute (ANSI). API-standards are developed in an open process that requires regular review of its more than 600 standards. [11].

API has issued following main guidelines and recommended practices (RP) for Hydraulic fracturing operations especially relevant to well integrity:

- API Guidance Document HF1: Hydraulic Fracturing Operations - Well Construction and Integrity Guidelines [12]

- API Standard 65-Part 2, Isolating Potential Flow Zones During Well Construction [13]

API states in the Guidance Document HF1 [12] that "Maintaining well integrity is a key design principle and design feature of all oil and gas production wells. Maintaining well integrity is essential for the two following reasons: 
1) To isolate the internal conduit of the well from the surface and subsurface environment. This is critical in protecting the environment, including groundwater, and in enabling well drilling and production.

2) To isolate and contain the well's produced fluid to a production conduit within the well."

In 12/2010 API released Standard 65-2, a special standard dealing with practices for isolating potential flow zones [13]. This standard refers not only to possible blowout situations threatening loss of well control, safety of personnel, the environment, and drilling rigs themselves. They also point towards the typical geological situations described in the Marcellus region (Fig. 3). A second objective is to help prevent Sustained Casing Pressure (SCP), also considered a serious industry problem.

API 65-2 [13] defines barrier elements as either physical or operational. Physical barrier elements are classified as hydrostatic (fluid columns), mechanical (eg seals, packer, plugs), or solidified chemical materials (= usually cement). Operational barriers are practices that result in activation of a physical barrier (eg flow detection devices). While physical barriers dominate the process, the total system reliability of a particular design is dependent on the existence of both types of barriers.

It is worth mentioning that both the casing design and process of setting casings, and the process of cementing design and cementing are interdependent. The quality of the cement sheath depends very much on the design and execution of the casing strings and associated equipment and the cementing process. Both elements individually and in combination have to create sustainable barriers for the lifetime of the well to avoid any fluid leakage and migration outside of the well system. This principles are very well illustrated in Figure 4 demonstrating the proposed well design by Cuadrilla for UK shale wells [14].

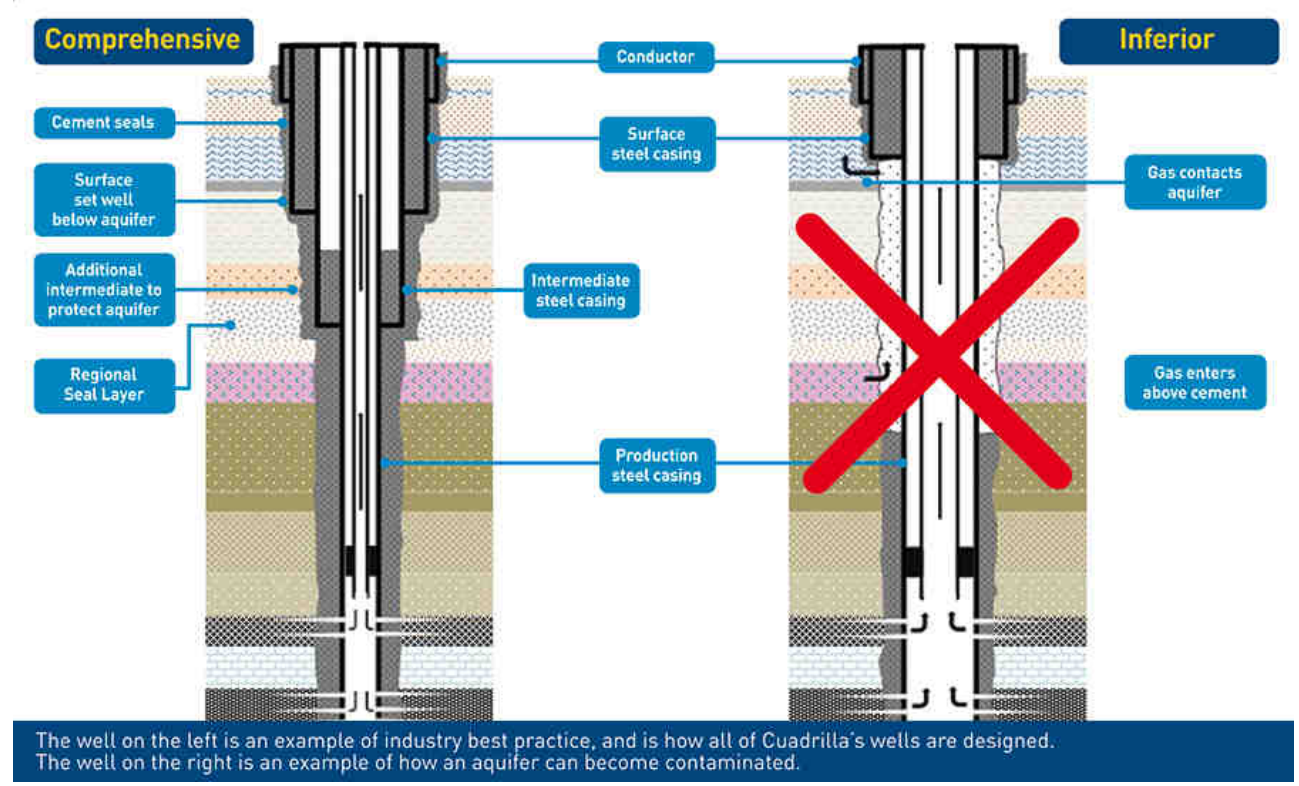

Fig. 4. Well design with (comprehensive) and without (inferior) intermediate casing [14] 
In Europe similar standards are in place already for a longer period (mainly driven by high offshore requirements), also with recent updates mainly triggered by the Macondo incident [Norway: Norsok D-010 [15] and UK: Well Integrity Guideline, July 2012 [16], and for Shale gas development in the UK (UK Onshore Shale Gas Well Guidelines) [17].

For additional overview see Reichetseder [8].

Being familiar with conventional gas production activities one can wonder, why shale gas (SG) production should be so different or even riskier than conventional gas where wells may pose risks because of high productivity and sometimes even high (abnormal) pressures and corrosive gases.

SG is different in following aspects:

- Formation pressures are rather low/moderate, short peak flowrate, low production rate

- Only during the short HF operation period loads are high and fluctuating

- The number of wells and HF activities is $c a 10$-fold or more compared to conventional

- The focus is on routine work to achieve scaling effects (,factory approach“)

- Water injection/disposal wells may cause earthquake problems

- Monitoring requirements are high because of high number of penetrations of groundwater formations

\section{Conclusions}

Well Integrity is a general requirement for any production/injection well (oil/gas/water). Shale gas wells with hydraulic fracturing (HF) have to consider the loads during treatment to maintain integrity over lifetime of the well. A proper Well Integrity Management System provides a sound basis for good environmental protection during shale gas operations.

In US the regulations for improvement of well design for shale gas have been developed both from industry practice and science, but also by lessons learned in shale gas activities. The individual states (Texas, Pennsylvania, Ohio, other) have adopted rigorous regulations since 2011 onwards.

In Europe regulations are well developed, exemplary the performance-based regulations in Norway and UK, which have been shaped by stringent offshore conditions and a general revision after the Macondo blowout. UK has developed a separate set of onshore regulations in order also to build trust for shale gas activities. The EU has developed a set of procedures which should build a common European standard. Individual countries will always have specific adaptations of general rules because of geology and other industry/regulatory history and experience.

\section{References}

[1] Wikipedia, https://en.wikipedia.org/wiki/Illusory_truth_effect.

[2] EIA 2015: Marcellus Region Drilling Productivity Report July 2015, U.S. Energy Information Administration. http://www.eia.gov/petroleum/drilling/pdf/marcellus.pdf.

[3] EPA 2015: External Review Draft. EPA/600/R-15/047a, June 2015. http://www.epa.gov/hfstudy.

[4] Osborn SG, Vengosh A, Warner NR, Jackson RB. Methane contamination of drinking water accompanying gas-well drilling and hydraulic fracturing. Proc National Acad Sci. 2011:108;8172-8176. DOI: 10.1073/pnas.1100682108.

[5] Molofsky LJ, Connor JA, Farhat SK, Wylie AS, Wager T. Methane in Pennsylvania water wells unrelated to Marcellus shale fracturing. Oil Gas J. 2011:54-67. http://www.ogj.com/1/vol-109/issue-49/explorationdevelopment/methane-in-pennsylvania-water-full.html. 
[6] Sueker JK, Clark BL, Cramer GH. Isotopic Forensic Techniques for Methane Source Discrimination. Stray Gas Incidence \& Response Forum, Cleveland, Ohio. July 23-25, 2012. www.ipec.utulsa.edu/conf2011/ sueker-27.pdf.

[7] Darrah TH, Vengosh A, Jackson RB, Warner NR, Poreda RJ. Noble gases identify the mechanisms of fugitive gas contamination in drinking-water wells overlying the Marcellus and Barnett Shales. Proc National Acad Sci. 2014. DOI: 10.1073/pnas.1322107111.

[8] Reichetseder P. Clean Unconventional Gas Production: Myth or Reality? The Role of Well Integrity and Methane Emissions, Swiss Bulletin for Applied Geology of SASEG/VSP and SFIG, 2014: 19(2);39-52. http://www.saseg.ch/cms/images/pdf/Publikationen/Medien/SwissBulletin_2-2014-lr.pdf.

[9] Ingraffea AR, Wells MT, Santoro RL, Shonkoff SBC. Assessment and risk analysis of casing and cement impairment in oil and gas wells in Pennsylvania, 2000-2012. Proc National Acad Sci. 2014:111(30);10955-10960. http://www.pnas.org/content/111/30/10955.full.pdf.

[10] Reichetseder P. Comment on SHIP News "New Numbers on well integrity failures", 30.10.2014. http://www.shale-gas-information-platform.org/areas/news/detail/article/comment-by-professor-reichetsederon-ship-news-new-numbers-on-well-integrity-failures.html.

[11] Emmert A. Oil and Natural Gas Industry Standards for Hydraulic Fracturing and Unconventional Wells. IEA Golden Rules for Gas Workshop, Washington: American Petroleum Institute, March 2012.

[12] API 2009: API Guidance Document HF1: Hydraulic Fracturing Operations - Well Construction and Integrity Guidelines. $1^{\text {st }}$ edition. Washington: American Petroleum Institute; 2009. www.shalegas.energy.gov/ resources/HF1.pdf.

[13] API 2010: API Standard 65-Part 2, Isolating Potential Flow Zones During Well Construction. $2^{\text {nd }}$ edition. Washington: American Petroleum Institute; 2010. http://www.shalegas.energy.gov/resources/65-2_e2.pdf.

[14] Cuadrilla 2014: Well Integrity - Cuadrilla Land Based Wells. http://www.cuadrillaresources.com/wpcontent/uploads/2012/02/DrillingPage-Well-Integrity-Document.pdf.

[15] NORSOK 2013: Well Integrity in drilling and well operations. Norsok Standard D-010, Rev. 4, June 2013, http://www.standard.no/en/webshop/Search/?search=Norsok+D-010+Rev.+4\#.

[16] Oil\&Gas UK 2012: Well Integrity Guidelines. Issue 1, July 2012. Oil and Gas UK 2012b, OP069, Available for purchase online, http://www.oilandgasuk.co.uk/cmsfiles/modules/publications/pdfs/OP069.pdf.

[17] UKOOG 2013: UK Onshore Shale Gas Well Guidelines, Exploration and appraisal phase. Issue 1 February 2013, UKOOG United Kingdom Onshore Operators Group. http://www.ukoog.org.uk/images/ ukoog/pdfs/ShaleGasWellGuidelines.pdf. 